\title{
Imaginário de graduandos de enfermagem sobre a pessoa com sofrimento psíquico: estudo sociopoético
}

\author{
Nursing students' imaginary regarding people with psychological distress: a socio-poetic study \\ Imaginario de los estudiantes de enfermería acerca de la persona con trastornos psíquicos: \\ estudio sociopoético
}

\author{
Leandro Andrade da Silva'; Iraci dos Santos ${ }^{\text {II }}$; Claudia Mara Melo Tavares ${ }^{I I I}$
}

\begin{abstract}
RESUMO: Ao ministrar a disciplina de saúde mental, torna-se necessário compreender o imaginário dos discentes sobre pessoas com sofrimento psíquico. Teve-se como objetivos: delinear o perfil de graduandos de enfermagem cursando a disciplina de psiquiatria e saúde mental; analisar a dimensão imaginativa de graduandos de enfermagem sobre pessoas com sofrimento psíquico. Utilizou-se o método sociopoético, em 2014, em Universidade do Rio de Janeiro-Brasil, junto a 24 estudantes. Aplicouse a vivência de lugares geomíticos, análise categorial e o estudo transversal. Constatou-se que $92 \%$, $88 \%$ e $71 \%$ dos alunos são, respectivamente, mulheres, de etnia branca, de 20 a 29 anos. Quanto ao imaginário, os dados produzidos pelo grupo pesquisador possibilitaram a delimitação das seguintes categorias temáticas: Múltiplas direções na vida; Difícil acesso na solidão; Metamorfose deambulante; Aridez em vida. Concluiu-se que a compreensão da dimensão imaginativa dos graduandos revelou uma ancoragem no imaginário social referente à loucura ao perceber as pessoas com aparência estigmatizada e aterradora.

Palavras-Chave: Enfermagem; psiquiatria; saúde mental; sofrimento psíquico.
\end{abstract}

\begin{abstract}
Lecturing in mental health requires an understanding of students' imaginaries regarding people with psychological distress. This study aimed to profile undergraduate nursing students enrolled in the discipline of psychiatry and mental health, and to examine the imaginative dimension in their views of people with psychological distress. The socio-poetic method was used with 24 students at a university in Rio de Janeiro, in 2014. The techniques applied were the experience of geo-mythical places, category analysis and cross-sectional study. The students were found to be $92 \%$ women, $88 \%$ Caucasians, and $71 \%$ 20-29 years old. As for their imaginaries, from the data produced by the research group it was possible to delimit the following thematic categories: multiple directions in life; difficult access in solitude; aimless metamorphosis; and barren lives. It was concluded that this understanding of the imaginative dimension in the students revealed it to be anchored in the social imaginary of madness in that such people are perceived as appearing stigmatized and terrifying.
\end{abstract}

Keywords: Nursing; psychiatry; mental health; psychological distress.

RESUMEN: Al impartir la asignatura de salud mental, se hace necesario comprender el imaginario de los estudiantes acerca de las personas con trastornos psíquicos. Tuvo como objetivos: describir el perfil de los estudiantes de enfermería que cursan la asignatura de psiquiatría y salud mental; analizar la dimensión imaginativa de los estudiantes de enfermería sobre personas con trastornos psíquicos. Se utilizó el método sociopoético, en 2014, en una Universidad de Río de Janeiro, Brasil, junto a 24 estudiantes. Se aplicó la experiencia de lugares geomíticos, el análisis categórico y el estudio transversal. Se encontró que el $92 \%, 88 \%$ y $71 \%$ de los estudiantes son, respectivamente, mujeres, caucásicos y tienen entre 20 y 29 años. En cuanto al imaginario, los datos producidos por el grupo investigador hicieron posible la delimitación de las siguientes categorías temáticas: múltiples direcciones en la vida; difícil acceso en la soledad; metamorfosis ambulante; aridez en vida. Se concluyó que la comprensión de la dimensión imaginativa de los estudiantes mostró un anclaje en el imaginario social referente a la locura al ver a las personas con apariencia estigmatizada y aterradora.

Palabras Clave: Enfermería; psiquiatría; salud mental; trastorno psíquico.

\section{INTRODUÇÃO}

Nas últimas décadas, profundas transformações ocor-reram na área da saúde e na formação dos profissionais de saúde mental (SM) no Brasil, por intermédio da política oficial de desativação de leitos psiquiátricos do Ministério da Saúde (MS) e a consequente construção de rede substitutiva baseada na atenção psicossocial $^{1}$.
Entretanto, na história da psiquiatria, o imaginário social sobre a loucura sempre foi carregado de signos relacionados à periculosidade. Num estudo desenvolvido com profissionais de SM, a representação social do sujeito em sofrimento psíquico ancorava em aspectos negativos, provando que, após inúmeras

IEnfermeiro. Doutorando do Programa de Pós-Graduação em Enfermagem da Universidade do Estado do Rio de Janeiro. Professor da Universidade Castelo Branco. Rio de Janeiro, Brasil. E-mail: proflandrade@gmail.com.

IIEnfermeira. Doutora em Enfermagem. Professora Titular da Universidade do Estado do Rio de Janeiro. Pesquisadora Visitante do Programa de PósGraduação em Enfermagem. Rio de Janeiro, Brasil. E-mail: iraci.s@terra.com.br.

IIIEnfermeira. Professora Titular e Coordenadora do Programa de Pós-Graduação em Enfermagem da Universidade Federal Fluminense. Niterói, Rio de Janeiro, Brasil. E-mail: claudiamarauff@gmail.com. 
transformações sociais e culturais ocorridas no atendimento em SM, estas foram incapazes de alterar o imaginário dos participantes do estudo ${ }^{2}$.

Ao longo da história da humanidade, a loucura assombrou o imaginário das pessoas devido ao medo do desconhecido, descontrolado, insensato e diferente. Como consequência, as construções sociais e a organização humana fizeram com que a pessoa com sofrimento psíquico (PCSP) fosse vítima das piores atrocidades que as pessoas pudessem fazer a seu semelhante, sem a intenção de perversidade. Práticas assistenciais que parecem absurdas se compreendidas no contexto atual, no passado eram concebidas como modernas. A busca pela cura de uma doença que é impossível retirar do corpo através de meios cirúrgicos, sem visualização em exames de imagem, gera, se mal realizada, uma destruição do ego do sujeito ${ }^{3}$.

Historicamente, a visão estigmatizada das PCSP os levou à exclusão, fazendo-os viver à margem social. Atualmente, o tratamento se faz por meio da rotulação, pela supressão de sintomas à base de medicações psicotrópicas e pela permanência desses indivíduos em instituições psiquiátricas com características asilares ${ }^{4}$.

Um dos desafios, impostos aos diversos processos da reforma psiquiátrica brasileira (RPB), é a transferência do atendimento aos clientes graves, internados há longos anos em hospitais psiquiátricos, para alternativas de tratamento na comunidade ${ }^{2}$. Devido aos efeitos deletérios da institucionalização prolongada, os indivíduos com vínculos sociais esmaecidos apresentam dificuldade para viver sozinhos e gerenciar suas vidas em sociedade. Alguns foram, ao longo dos anos, incluídos em serviços residenciais terapêuticos, e outros, ainda não.

Pensando na perspectiva do cuidar em SM, nos interessou a compreensão do imaginário de graduandos de enfermagem sobre PCSP, que ainda não tiveram contato com o conteúdo teórico da disciplina de enfermagem psiquiátrica e saúde mental.

Portanto, foram formulados os objetivos: delinear o perfil de graduandos de enfermagem cursando a disciplina de psiquiatria e saúde mental; e analisar a dimensão imaginativa de graduandos de enfermagem sobre pessoas com sofrimento psíquico.

\section{REvisão DE LiteratuRA}

Dados do MS revelaram que, no Brasil, no ano de 2011, havia $32.284^{5}$ indivíduos internados em hospitais psiquiátricos. Esse é um dado assustador, considerando a luta histórica de diferentes atores sociais para o fim dos manicômios nesse país. As pessoas que ainda se encontram nesses espaços representam uma lacuna à RPB não preenchida. Elas seriam as remanescentes dos diferentes processos de reforma.

Alguns hospitais psiquiátricos realizaram mudanças estéticas em enfermarias para proporcionar um ambiente humanizado. Atualmente, em função do envelhecimento e da impossibilidade logística e/ou assistencial, quase a totalidade de clientes idosos permanecem internados. Apesar de mais de uma década da promulgação da lei $\mathrm{n}^{\circ} 10.216 / 2001$, que exigiu o progressivo fechamento de espaços com características asilares, ainda há pessoas internadas ${ }^{6}$.

Existem, portanto, questões éticas urgentes. Uma, constantemente discutida, refere-se ao contexto da desinstitucionalização, que caracterizou os debates nas últimas décadas na área de SM. Sua ênfase relaciona-se ao retorno dos indivíduos com transtornos mentais (TM) às comunidades, visando resgatar sua integridade, identidade e vida familiar, comunitária e profissional.

Restaram outros internados sem a contemplação de diferentes tentativas de desinstitucionalização. Então, pensar sobre o cuidado ofertado à clientela que envelheceu internada em hospitais psiquiátricos se faz urgente, para que ocorram transformações nos modelos de prática ${ }^{2,3}$.

Importa pensar sobre como os clientes denominados de crônicos, ou também de longa permanência, envelheceram internados em instituições psiquiátricas. Isso porque o aumento do número de idosos no Brasil impõe mudanças profundas nos modos de conceber e viver o envelhecimento na sociedade contemporânea.

As PCSP, que historicamente carregaram signos repletos de estigmas negativos, agora possuem mais um, normalmente associado ao processo do envelhecer, sendo um dos pilares o declínio biológico, ocasionalmente acompanhado de outras doenças e dificuldades funcionais com o avançar da idade?

No Brasil, de forma veloz, rumo a um perfil demográfico cada vez mais envelhecido, verifica-se a necessidade de adequações nas políticas sociais, particularmente aquelas destinadas ao atendimento de crescentes demandas nas áreas da saúde, previdência e assistência social. Há uma transição demográfica caracterizada pela mudança no perfil epidemiológico, na qual as doenças infectocontagiosas encontram-se mais controladas do que no passado. Entretanto, verifica-se um aumento vertiginoso nos casos de doenças crônico-degenerativas na população idosa?

Ultimamente, na área de saúde, desgastes vêm ocorrendo; muitas são as reclamações da população, quanto ao desgaste e a indiferença, bem como pela maneira inadequada de atender de alguns profissionais. Para minimizar e mudar essa realidade, desde 2001, o MS preconiza a humanização do atendimento, por intermédio de um programa específico ${ }^{5}$.

Alguns estudiosos alertam a adoção histórica do modelo biomédico, que responde apenas às necessidades vitais do corpo físico. Urge refletir sobre a insuficiência de seu enfoque prioritário nas múltiplas dimensões corporais, nas causas físicas e psíquicas das 
doenças. A contradição dessa opção com o discurso da integralidade do cliente, alvo da atenção humanista pretendida pela enfermagem, provoca conflitos naqueles que, efetivamente, a praticam ${ }^{8}$.

Embora cuidar seja um atributo inerente aos seres humanos, esta atividade, especialmente na enfermagem, torna-se algo genuíno e peculiar. Portanto, quanto ao cuidado integral, ressalta-se sua efetividade ao ser desenvolvido junto com o cliente e, assim, com este convivendo e interagindo nos seus movimentos de ser e de estar nessa condição do viver ${ }^{8}$.

\section{Metodologia}

Para a caracterização dos participantes do estudo, optou-se pela abordagem quantitativa, aplicando-se o método analítico-descritivo e a técnica de entrevista estruturada individual. A investigação foi desenvolvida em uma universidade pública federal do Rio de Janeiro - Brasil. Participaram do estudo 24 graduandos em enfermagem, matriculados na disciplina de saúde mental e psiquiatria, em 2014, sendo esse o critério de inclusão para participar da pesquisa.

A produção de dados realizou-se de abril a maio de 2014. Isso foi necessário para evitar o contato dos alunos com o conteúdo teórico da disciplina, influenciando seu imaginário acerca das PCSP. O instrumento de produção de dados foi composto pelas variáveis: sexo, cor/etnia autodeclarada, faixa etária, local de residência, natureza da residência, renda salarial, estado de união, constelação familiar, crença religiosa, vínculo empregatício, realização de atividades de lazer, participação em atividades culturais, e participação em eventos científicos.

Os dados produzidos foram submetidos à estatística descritiva simples, posteriormente organizados, agrupados, tabulados e representados graficamente.

Para analisar a dimensão imaginativa dos graduandos de enfermagem sobre as PCSP, escolheu-se o método sociopoético, qualitativo, descritivo.

A Sociopoética, em seus princípios filosóficos, compreende toda prática social de produção de conhecimento que afirma: a importância do corpo na construção do imaginário, sendo a base para as abstrações; a importância das culturas dominadas, de suas categorias e dos conceitos por elas produzidos; o papel da criatividade artística na construção de saberes; a valorização dos participantes de pesquisa como corresponsáveis pelos conhecimentos produzidos e o sentido espiritual, humano, das formas e dos conteúdos do saber ${ }^{6}$.

Entre seus fundamentos teóricos, destaca-se que essa abordagem de pesquisa, educação e cuidado é um desenvolvimento da Pedagogia do Oprimido de Paulo Freire, uma continuação do amadurecimento desta, que ele desenvolveu durante sua vida? .
Todos os saberes são iguais em direitos é uma premissa da Sociopoética. Participam de maneira igual os facilitadores da pesquisa e o Grupo-Pesquisador (GP). Ressalte-se que o significado de igualdade não é semelhante para os membros desse grupo, pois os facilitadores, tal como o pesquisador institucional, não produzem dados; esses trazem uma contribuição própria na leitura dos dados produzidos, que é dialogicamente confrontada à leitura do GP durante a contra-análise ${ }^{9}$.

Tal modalidade difere da pesquisa participante porque não apresenta intencionalidade conscientizadora nem a predominância do público-alvo em termos socioeconômicos. A sociopoética busca a resolução de problemas; realiza o diagnóstico de realidade do grupo-alvo; está centrada como a pesquisa participante. Assim, configura-se como outra leitura da pedagogia de Paulo Freire, acompanhada de outras inspirações, fundamentações ou teorizações tais como a Análise Institucional de René Lourau, a Esquizo - análise de Gilles Deleuze e Felix Guattari -, o Teatro do Oprimido de Augusto Boal e a Escuta Mitopoética de René Barbier ${ }^{9,10}$.

A técnica de pesquisa aplicada foi a Vivência de Lugares Geomíticos (VLG), após dinâmicas de sensibilidade e de relaxamento. Essas dinâmicas possibilitam o rebaixamento de pressões normativas, para que os integrantes do GP se expressem livremente, enfraquecendo censuras e possibilitando a fluidez dos conteúdos pré-conscientes e inconscientes. As intenções e razões ao propor um momento de relaxamento antes dessas oficinas têm raízes nas proposições teóricas de Freud e Marx, ambos interessados na liberação do inconsciente, sendo o primeiro em nível individual e o segundo, em nível coletivo ${ }^{11}$.

A VLG foi operacionalizada em uma das seis etapas do $\mathrm{GP}^{10}$, cujo dispositivo analítico se inspira nos fundamentos teóricos da Sociopoética, conforme se descreve:

- Instituição do GP- identificação pessoal e codificação numérica de cada participante; apresentação e negociação do tema e da questão norteadora da pesquisa, sendo escolhida: Se o indivíduo com sofrimento psíquico fosse um lugar geomítico como ele seria?

Produção de dados por meio da VLG, utilizandose o formulário contendo os lugares geomíticos - terra, poço, falha, caminho, arco-íris e gruta - e o espaço para o registro das respostas com uma frase completa, de cada participante. Posteriormente, foi feita uma análise individual sobre cada resposta dos participantes, visando delimitar a estrutura do pensamento individual.

- Análise do pesquisador institucional/facilitador sobre as respostas e temas delimitados pelos participantes, com vistas à delimitação dos temas grupais.

- Contra-análise do GP sobre a organização do pesquisador a partir dos temas produzidos.

- Organização dos dados em quadros para a validação do GP referente à análise categorial temática feita pelo pesquisador institucional. 
- Divulgação dos achados científicos e síntese cultural, considerando a avaliação, pelo GP, do desenvolvimento das oficinas sociopoéticas.

A análise dos dados produzidos tem a finalidade de compreender os temas individuais - a estrutura do pensamento individual e, em seguida, os grupais que formam as subcategorias e as categorias temáticas a serem analisadas. O levantamento dos temas predominantes em cada lugar geomítico considera a descrição de estudos sociopoéticos descritos na seção de resultados.

Neste trabalho, escolheu-se o estudo transversal, referente ao levantamento dos temas que se contrapõem nos mesmos lugares geomíticos, e dos temas isolados ou diferenciados, presentes em lugares diferentes 9.

Ressalta-se que todos participantes assinaram o Termo de Consentimento Livre e Esclarecido, conforme recomenda a Resolução n ${ }^{\circ} 466 / 2012$, referente às pesquisas envolvendo seres humanos. $\mathrm{O}$ projeto de pesquisa que originou este recorte foi submetido à avaliação do Comitê de Ética em Pesquisa da Secretaria Municipal de Saúde do Rio de Janeiro, obtendo aprovação mediante o Parecer n ${ }^{\circ} 526.891$.

\section{Resultados e Discussão}

Inicialmente, descrevem-se as características individuais dos membros do GP. Verificou-se que a maioria (22) é do sexo feminino, de etnia branca autodeclarada (17), enquanto apenas um estudante se autodeclarou de cor negra. Todos participantes tinham idade superior a 20 anos, ressaltando-se que a maioria (21) situava-se na faixa etária de 20 a 29, enquanto na de 40 a 49 anos só foi encontrada uma pessoa. Ver Tabela 1.

Nesse resultado, corroboram-se os dados encontrados nesta investigação devido a sua semelhança aos do último Exame Nacional de Desempenho de Estudantes (ENADE), realizado pelo Ministério da Educação, e destinado à avaliação de cursos de graduação em enfermagem no ano de $2007^{9}$.

Esses também convergem para outros estudos de enfermagem, nos quais verificou-se $65,9 \%$ de mulheres e $34,1 \%$ de homens com prevalência de idade abaixo dos $24 \operatorname{anos}^{12}$.

Quanto à constelação familiar, somente um graduando de enfermagem declarou ter um filho. Quando questionados sobre esse fato, os participantes da entrevista alegaram que pretendiam priorizar seus estudos antes de constituírem família ou terem filhos, acreditando que, após a conclusão destes, poderiam dar uma qualidade de vida melhor às futuras famílias.

Possivelmente pelo fato de a universidade, campo da pesquisa, situar-se num município do Rio de Janeiro, justifique-se a semelhança dos dados quanto ao local de residência dos participantes, encontrando- -se10 graduandos, respectivamente, na capital do Rio de Janeiro e na região oceânica. Ressalta-se que a maioria, 16 , tem residência própria, conforme a Tabela 1.

Constatou-se o predomínio do catolicismo adotado por nove graduandos, sendo esse um fato sempre registrado pelo Instituto Brasileiro de Geografia e Estatística (IBGE) concernente à população

TABELA 1: Características individuais do grupo-pesquisador. Rio de Janeiro, 2014. $(\mathrm{N}=24)$

\begin{tabular}{|c|c|c|}
\hline Características & $f$ & $\%$ \\
\hline \multicolumn{3}{|l|}{ Sexo } \\
\hline Masculino & 2 & 8 \\
\hline Feminino & 22 & 92 \\
\hline \multicolumn{3}{|l|}{ Etnia autodeclarada } \\
\hline Branca & 17 & 71 \\
\hline Parda & 6 & 25 \\
\hline Negra & 1 & 4 \\
\hline \multicolumn{3}{|l|}{ Faixa etária } \\
\hline 20 a 29 anos & 21 & 88 \\
\hline 30 a 39 anos & 2 & 8 \\
\hline 40 a 49 anos & 1 & 4 \\
\hline \multicolumn{3}{|l|}{ Constelação familiar } \\
\hline Sem filhos & 23 & 96 \\
\hline Com filhos & 1 & 4 \\
\hline \multicolumn{3}{|l|}{ Local de residência } \\
\hline Rio de Janeiro & 10 & 42 \\
\hline Região oceânica & 10 & 42 \\
\hline Baixada fluminense & 4 & 16 \\
\hline \multicolumn{3}{|l|}{ Natureza da residência } \\
\hline Própria & 16 & 67 \\
\hline Alugada & 8 & 33 \\
\hline \multicolumn{3}{|l|}{ Crença religiosa } \\
\hline Católica & 9 & 41 \\
\hline Protestante & 6 & 27 \\
\hline Espírita & 3 & 14 \\
\hline Sem religião & 2 & 10 \\
\hline Outras & 1 & 4 \\
\hline Não informada & 1 & 4 \\
\hline \multicolumn{3}{|l|}{ Vínculo empregatício } \\
\hline Estatutário & 1 & 4 \\
\hline Bolsista & 9 & 38 \\
\hline CLT & 2 & 8 \\
\hline \multicolumn{3}{|l|}{ Renda salarial } \\
\hline Sem renda & 12 & 50 \\
\hline Com renda & 12 & 50 \\
\hline \multicolumn{3}{|c|}{ Realização de atividades de lazer } \\
\hline Sim & 21 & 87 \\
\hline Não & 3 & 13 \\
\hline \multicolumn{3}{|c|}{ Participação em atividades culturais } \\
\hline Sim & 16 & 84 \\
\hline Não & 08 & 16 \\
\hline \multicolumn{3}{|c|}{ Participação em eventos científicos } \\
\hline Sim & 17 & 71 \\
\hline Não & 7 & 29 \\
\hline
\end{tabular}


brasileira $^{13}$. Referente à renda salarial, 12 participantes declararam não possuí-la. Os demais recebiam auxílio financeiro de seus pais, possuíam bolsas de estudos, principalmente as de iniciação científica.

Quanto ao lazer e atividades culturais, quase a totalidade do GP afirmou participar das práticas de idas ao cinema, praia, shopping, teatro, museus, shows e atividades físicas.

Referente à participação em eventos científicos, a maioria (17) informou participar somente de eventos científicos nacionais, destacando-se os de enfermagem, aqueles relacionados às áreas de saúde mental, obstetrícia, ortopedia e saúde coletiva.

\section{Imaginário de graduandos de enfermagem sobre pessoas com sofrimento psíquico}

A análise categorial dos dados produzidos nas oficinas sociopoéticas, aplicando a vivência de lugares geomíticos (Terra, Poço, Falha, Caminho, Arco-íris, Gruta), possibilitou a delimitação de categorias temáticas construídas a partir da compreensão do significado das estruturas do pensamento individual e do pensamento grupal dos membros do GP. Aqui, são apresentadas quatro categorias temáticas, compostas pelas 112 subcategorias, encontradas nos lugares geomíticos que lhes deram origem: Múltiplas direções na vida; Difícil acesso na solidão; Metamorfose deambulante; Aridez em vida, conforme se observa na Tabela 2.

\section{Múltiplas direções na vida}

$\mathrm{O}$ estudo transversal favoreceu a compreensão da estrutura do pensamento do GP, expressa nesta categoria por 20 subcategorias: aberto à vida; aterrado e interminável; busca de iluminação; caminho em espiral; cíclico, intermitente; claro e iluminado; colorido, marcante, sem uniformidade; desviante; desviante e iluminado; direções que levam ao mesmo lugar; esperança em dias melhores; água em ebulição; força interior; inquietação isolada; passageiro solitário; passagem sem obstáculos; passagem solitária e difícil; repleto de esperanças; um fluxo constante.

Essas subcategorias representam a dificuldade de entender a convivência da pessoa com sofrimento psíquico (SP), principalmente a que envelheceu no manicômio, de acordo com as respostas do GP, sobretudo aquelas obtidas nos lugares Caminho e Gruta:
Se a pessoa com sofrimento psíquico fosse um Caminho, ela seria controversa e de difícil acesso em sua solidão. Seu caminho seria cíclico, uma espiral em busca de iluminação, ... uma busca de atenção. Difícil acesso para relacionamento, um ser fora da realidade e prisioneiro do passado. Pessoa solitária, difícil, vazia em busca de isolamento, com múltiplas personalidades necessitando união entre as diferenças. (Grupo-Pesquisador)

Ressalta-se que os membros do GP acreditam no que dizem sobre as pessoas consideradas como loucas, inclusive, receiam o acesso a estas. Eles intuem que a pessoa com sofrimento psíquico (PCSP) se isola para evitar a realidade daquelas consideradas pessoas normais e de um relacionamento pessoal que possa levá-la de volta ao passado.

É dramático pensar que tais indivíduos são diferentes e que os ditos normais, diante dos constantes estresses advindos das pressões, sentimentos e sobrecarga de emoções da atualidade existencial estão isentos de situações que propiciem ocultar a revolta, a solidão, a tristeza e a infelicidade, usando a capa da reconhecida loucura ${ }^{2-4,14,15}$.

Isso acontece porque as pessoas, diante de um viver com certas dificuldades, reagem com o seu potencial de reação humana, cabendo aos normais e profissionais de saúde procurar entendê-las desde a história de vida de cada uma delas ${ }^{10}$.

\section{Difícil acesso na sua solidão}

Esta categoria foi composta por 18 subcategorias: anormalidade genética; clamando por atenção; de difícil acesso em sua solidão; difícil acesso para relacionamento; difícil acesso; difícil acesso pela solidão; difícil e complicado; dificuldade de atenção; dificuldade de retorno à realidade; ignorado; impenetrável; incolor; incompreensível e apagado; infertilidade; inimaginável; inimaginável, em busca do pote de ouro, uma pessoa com seus momentos difíceis, encontradas predominantemente no lugar geomítico Gruta. No imaginário do GP, a Gruta/Pessoa com sofrimento psíquico seria:

Aberta à vida mesmo que, arriscada, mas repleta de esperanças. Caminhando em espiral em busca de iluminação, apesar de caótica e desorganizada.

Entretanto, a Falha/PCSP seria, também...

Aberta à vida...cíclica e intermitente. (Grupo-Pesquisador)

TABELA 2: Categorias temáticas representativas da dimensão imaginativa acerca da pessoa com sofrimento psíquico.

\begin{tabular}{lccccccc}
\hline Categoria & Terra & Poço & Falha & Caminho & Arco-Íris & Gruta & Total \\
\hline Múltiplas direções na vida & 1 & 2 & 3 & 8 & 1 & 5 & 20 \\
Difícil acesso na sua solidão & 2 & 1 & 4 & 2 & 3 & 6 & 18 \\
Metamorfose deambulante & 11 & 8 & 7 & 4 & 11 & 2 & 43 \\
Aridez em vida & 5 & 7 & 1 & 3 & 8 & 7 & 31 \\
TOTAL & 19 & 18 & 15 & 17 & 23 & 20 & 112 \\
\hline
\end{tabular}


Observou-se que as respostas referentes à Gruta/ PCSP são dicotômicas; ora ela é iluminada e ora busca a iluminação, enquanto a Falha/PCSP mostra certa ambiguidade. Fazendo uma analogia à mitologia grega, tais lugares seriam como uma caixa de pandora, visto que para o GP, a Gruta guarda a esperança em dias melhores e a Falha revelaria uma vivência cíclica e intermitente.

Para os profissionais de saúde, possivelmente, tais dias virão quando houver mudança na perspectiva de cuidados respeitando a integralidade e dignidade humana da pessoa com sofrimento psíquico ${ }^{3,5}$.

\section{Metamorfose deambulante}

Esta categoria reúne o maior número de subcategorias, conforme se descreve: afundando em vida; ambiguidade; amedrontado; apagado em finitude; arriscado e indefinido; ausência de perspectiva; caótica; confuso; controverso na busca de um sentido; danificado, destruído; diferente e infinito; diferente em busca de atenção; dura e maleável; fora da normalidade, diferente; inconstante; indefinido; instável; intensa dualidade; invadido por forças maiores; metamorfose pessoal para o negativo; múltiplas personalidades; necessidade de aceitação; necessidade de atenção; necessidade de transformação; necessidade de união entre as diferenças; metamorfoses; onde se guarda e revela; paradoxal; personalidade com diversas rachaduras; pessoa fragmentada; pessoa partida; profundo; profundo e ativo; profundo e obscuro; profundo, vazio e isolado; ruptura de personalidade; sem terminalidade; ser amordaçado; ser cindido. Tais subcategorias foram encontradas, predominantemente, nos lugares geomíticos Terra e Arco-Íris, de acordo com a descrição da Tabela 2.

As denominações atribuídas às 43 subcategorias revelam e caracterizam a transversalidade deste estudo, pois mostra a diversidade de situações e aparências apresentadas pela PCSP. Assim, o GP imaginou que se a PCSP/Terra e/ou Arco-Íris seria:

Uma metamorfose pessoal em múltiplas direções e formada por múltiplas personalidades, necessitando união entre as diferenças. Pessoa carente..., provavelmente tem diversas necessidades de: aceitação, atenção, transformação... e, principalmente, de união entre as diferenças. (Grupo-Pesquisador)

Analisando esse imaginário de um grupo formado por estudantes jovens e de adultos jovens, sem contato anterior com a disciplina de psiquiatria e saúde mental, bem como participação em estágios em instituições que atendem PCSP, há que se intuir sobre uma realidade do viver onde as pessoas sadias e as supostamente sadias, e onde os profissionais e os clientes possam ser igualmente pessoas, cidadãos e sujeitos; e por serem humanos e mortais, vivem predispostos às suas individualidades e singularidades e, portanto, suas metamorfoses serão respeitadas em sua dignidade humana, mesmo que em múltiplas direções.
Nesse sentido, concorda-se com o conceito de Domínio do mundo, no qual se compartilha o Domínio do eu referente aos pensamentos, anseios, visões de mundo com outras pessoas em seu meio social. Isso caracteriza o centro dos esforços do profissional para compreender os problemas vivenciados pela PCSP por meio de um cuidado holístico, integral. Isso é ajudá-lo no que lhe aflige e atrapalha seu viver cotidiano ${ }^{11}$.

\section{Aridez em vida}

Nesta categoria, predominou o Arco-íris, arraigado de elementos negativos, caracterizados, predominantemente, por expressões como sem vida, sem finalidade, sem brilho, podendo ser expresso pelas seguintes falas do GP:

Eu imaginei um arco-íris preto e branco, sem vida, sem brilho. Seria todo preto. (Grupo-Pesquisador)

Atrelado aos aspectos negativos, a Gruta evidenciou elementos de um imaginário ancorado na história da loucura, que seria sinônimo de periculosidade ${ }^{16}$, a exemplo das expressões utilizadas pelo GP: vazio e apavorante, solitário e perigoso.

Nas falas sobre este imaginário dos graduandos de enfermagem, a Gruta seria:

Uma caverna cheia de rochas pontiagudas, escura e úmida. Seria feia e com muitos morcegos. (Grupo-Pesquisador)

Verifica-se, com as análises das categorias, que o GP possui uma imagem negativa, contrastante com elementos positivos, com características afetivas, evidenciando um paradoxo no seu imaginário, que pode convergir com o imaginário do senso comum acerca da loucura e do sujeito em sofrimento psíquico.

Percebe-se a existência de diferentes entraves sociais, emocionais e/ou culturais, que corroboram para reforçar, junto ao senso comum, a imagem negativa da PCSP, pois ela ainda é considerada socialmente um ser despossuído de razão, agressivo, perigoso e incapaz de viver em sociedade. Essa relação, lamentavelmente, ainda é categorizada em termos de normal versus desviante anormal, revelando que a sociedade não está preparada para o desafio de acolher e cuidar dessas pessoas. A visão preconceituosa em relação ao fenômeno da doença mental continua reforçando a exclusão e a marginalização social e afetiva ${ }^{4}$.

\section{Conclusão}

A dimensão imaginativa dos participantes da pesquisa revelou, pela associação da VLG com as PCSP, aspectos negativos quanto à sua própria percepção referente ao envelhecimento nos espaços manicomiais, vítima de uma assistência estigmatizante e excludente.

Nessa dimensão imaginativa, intui-se que as PCSP têm um longo e cruzado caminho a percorrer antes do seu resgate para a sociedade. Assim, conclui-se que 
a compreensão do imaginário do grupo-pesquisador revelou sua possível ancoragem no imaginário social referente à loucura e aos sujeitos que padecem desta enfermidade.

\section{REFERÊNCIAS}

1.Pinheiro R, Guljor AP, Silva Junior AG. Necessidades e práticas na desinstitucionalização da clientela de longa permanência institucional: uma proposta avaliativa sobre a relação entre demanda e oferta de cuidado. In:Pinheiro R, Gujor AP, Silva Junior AG, Mattos RA, organizadores. Desinstitucionalização da saúde mental: contribuições para estudos avaliativos. Rio de Janeiro: ABRASCO; 2007. p.13-40.

2.Silva LA, Gomes AMT, Oliveira DC, Souza MGG. Social representations of aging in institutionalized psychiatric patients. Esc Anna Nery[periódico na internet]. 2011 [cited in 2015 March 07]; 15(1). Available from: http://www.scielo.br/scielo.php? script =sci_arttex$\mathrm{t}$ \&pid $=$ S1414-81452011000100018

3.Silva LA. As representações sociais de profissionais de saúde acerca do paciente psiquiátrico: aspectos descritivos e de zona muda [dissertação de mestrado] Rio de Janeiro: Universidade do Estado do Rio de Janeiro; 2011. 4. Maciel SC, Barros DR, Camino LF, Melo JRF. Social representations of familiar membersconcerningmadness and the psychiatric hospital.Temas psicol. [periódico na Internet]. 2011 [cited in 2015 Feb 15]. 19(1): 193-204. Available from: http://pepsic. bvsalud.org/scielo.php? script $=$ sci_arttext\&pid $=$ S1413 389X2011000100015\&lng=pt.

5.Ministério da Saúde (Br). Saúde mental em dados. Brasília (DF): Ministério da Saúde; 2012.

6.Santos I dos, Silva LA. Vulnerability of hiv/aids in patients with mental disorders: an integrative review. Online braz j nurs [Internet]. 2013 June [cited in mar 2015]; 12: 393-410. Available from:http://www.objnursing.uff. br/index.php/nursing/article/view/3868 Uchoa, 2001 7.Ministério da Saúde (Br). Relatório Final da IV Conferência Nacional de Saúde Mental - Intersetorial. Brasília (DF):Conselho Nacional de Saúde; 2010. Disponível em: http://portal.saude.gov.br/portal/arquivos/pdf/2011_2_1 relatorio_IV.pdf.

8.Santos I dos, Caldas, CP, Erdmann AL, Gauthier J, Figueiredo NMA. Cuidar da integralidade do ser: perspectiva estética/sociopoética de domínio da enfermagem. Rev enfermUERJ. 2012; 20: 4-9.

9.Petit SH, Gauthier J, Santos I dos, Figueiredo NMA. Introduzindo a sociopoétca. In: Santos I dos, Gauthier J, Figueiredo NMA, Petit SH. Prática de pesquisa em ciências humanas e sociais: abordagem sociopoética. São Paulo: Atheneu; 2005. p. 1-16.

10.Gauthier J. O oco do vento: metodologia da pesquisa sociopoética e estudos transculturais. Curitiba (PA): CRV; 2012.

11.Santos I dos, Silva LA, Gauthier J, Guerra RGM. Contributions of social poetics on the scientific production regardingnursing care: an integrativeliterature review. Rev. Eletr. Enferm. [periódicona Internet]. 2013;15:243 52. [cited 2015 Apr 15]. Available from: http://dx.doi. org/10.5216/ree.v15i1.20888.

12. Wetterich NC, Melo MRAC. Perfil sociodemográfico do aluno do curso de graduação em enfermagem. Rev. Latino-Am Enfermagem. [periódico na Internet]. 2007 [citado em10 fev 2015]; 15: 404-10. Disponível em: http://www.scielo.br/scielo.php?script =sci arttext\&pid =S0104-11692007000300007\&lng $=$ en $\& n r m=$ iso.http://dx.doi.org/10.1590/S010411692007000300007.

13. Instituto Brasileiro de Geografia e Estatística (Br). Indicadores sociodemográficos prospectivos para o Brasil 1991-2030. Brasília (DF): IBGE; 2006.

14. Barker PJ. The Tidal Model: developing a person - centred approach to psychiatric and mental health nursing. Perspectives in psychiatric care.In: Alligood MR, Tomey AM. Nursing theorists and their work. Missouri (USA): Elsevier; 2013.37(3): 79-87.

15.Santos I, Silva LA, Silva AV. Perspectiva estética e sociopoética ao cuidar de pessoas com sofrimento psíquico: apropriação da Teoria Tidal Modal. Rev enferm UERJ. 2014; 22: 815-20.

16.Foucault M. História da loucura: na idade clássica. São Paulo: Perspectiva; 2008. 